\title{
Association of physical restraint requirement with unfavorable neurologic outcomes in subarachnoid hemorrhage
}

Kyoko Akiyama

Kagawa University Hospital

Akihiko Inoue

Kagawa University Hospital

Toru Hifumi ( $\nabla$ hifumitoru@gmail.com )

Faculty of medicine, Kagawa University

Kentaro Nakamura

Kagawa University Hospital

Takuya Taira

Kagawa University Hospital

Shun Nakagawa

Kagawa University Hospital

Keisuke Jinno

Kagawa University Hospital

Arisa Manabe

Kagawa University Hospital

Sayaka Kinugasa

Kagawa University Hospital

Hikaru Matsumura

Kagawa University Hospital

Hajime Shishido

Kagawa University Hospital

Shota Yokoyama

Kagawa University Hospital

Tomoya Okazaki

Kagawa University Hospital

Hideyuki Hamaya

Kagawa University Hospital

Koshiro Takano

Kagawa University Hospital

Kazutaka Kiridume 
Kagawa University Hospital

Natsuyo Shinohara

Kagawa University Hospital

Kenya Kawakita

Kagawa University Hospital

Yasuhiro Kuroda

Kagawa University Hospital

\section{Original research}

Keywords: physical restraint, neurological outcome, subarachnoid hemorrhage, delirium

Posted Date: October 14th, 2020

DOI: https://doi.org/10.21203/rs.3.rs-89487/v1

License: (c) (i) This work is licensed under a Creative Commons Attribution 4.0 International License. Read Full License 


\section{Abstract}

\section{Background}

The association between physical restraint requirement and neurological outcome in patients with subarachnoid hemorrhage (SAH) has not been fully examined. The aim of this study was to examine the association between physical restraint and neurological outcomes in patients with SAH.

\section{Methods}

A single-center, retrospective study was conducted on patients with acute phase SAH treated for $>72 \mathrm{~h}$ in the intensive care unit from 2014 to 2020. Patients were divided into three groups based on the amount

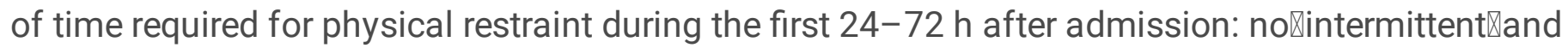
continuous use of physical restraint. Unfavorable neurologic outcome, assessed using the modified Rankin scale upon hospital discharge, has been considered as primary end-point.

\section{Results}

Overall, 101 patients were included in the study, with 52 patients $(51.5 \%)$ having unfavorable neurological outcomes. Among them, 46 patients (45.5\%) did not use physical restraint, and 55 (54.5\%) patients used physical restraint during the first 24-72 $\mathrm{h}$ after admission: 26 (25.7\%) intermittent and 29 (28.7\%) continuous. Multivariable logistic regression analysis showed that continuous use of physical restraint during the first 24-72 $\mathrm{h}$ after admission compared to no physical restraint was significantly associated with unfavorable neurological outcomes in patients with SAH (odds ratio [OR], 3.31; 95\% confidence interval [Cl], 1.02-11.54; $\mathrm{p}=0.045]$ ).

\section{Conclusions}

Continuous use of physical restraint during the first $24-72 \mathrm{~h}$ after admission was more significantly associated with unfavorable neurological outcomes than no physical restraint among patients with SAH during the acute phase.

\section{Background}

Physical restraint defined as "any manual method, physical, or mechanical device, material, or equipment that immobilizes or reduces the ability of a patient's movement" have been commonly indicated for patients with brain dysfunction in neurocritical care (1-3). Its effect on outcomes of critically ill adult patients remains controversial as no RCTs have compared its safety and efficacy $(1,4)$.

Agitation, consciousness fluctuation, and delirium after a subarachnoid hemorrhage (SAH) have been associated with unfavorable neurological outcome(5-7). However, the association between physical restraint requirement and neurological outcomes in patients with SAH has not been fully examined. 
Therefore, this study aimed to examine the association between physical restraint requirement and neurological outcome in patients with SAH.

\section{Methods}

\section{Study design and setting}

This single-center, retrospective study was conducted at the Kagawa University Hospital, a 613-bed teaching institution with an 8-bed intensive care unit (ICU) managed by a neurointensivist. Medical records were reviewed with the approval of the institutional review board (approval number: 2020-053) and in accordance with the ethical standards established in the 1964 Declaration of Helsinki and its later amendments. The requirement for patient consent was waived due to the retrospective nature of the study.

\section{Study participants and inclusion criteria}

We included patients aged $\geq 18$ years who were consecutively admitted to the ICU between July 1,2014 , and July 31, 2020, with a confirmed diagnosis of aneurysmal SAH. Patients who met the following inclusion criteria were included: acute phase of SAH treated for $>72 \mathrm{~h}$ in the ICU. Exclusion criteria were patients who were not performed treatment (coil or clip) for aneurysmal SAH, patients provided with comfort care only or patients admitted to the ICU for $<72 \mathrm{~h}$. Additionally, those with Hunt and Kosnik (H \& K) grade 5, or Richmond Agitation-Sedation Scale (RASS) -5 or neuromuscular blockade use during the first $24-72 \mathrm{~h}$ after admission were excluded.

\section{General management of SAH in the ICU}

All patients were managed in accordance with Guidelines for the Management of Aneurysmal Subarachnoid Hemorrhage by the American Heart Association/American Stroke Association(8). In addition to the general intensive care, all patients were monitored for clinical deterioration or cerebral infarction development due to delayed cerebral ischemia (DCl). Fever was treated aggressively with acetaminophen, nonsteroidal anti-inflammatory medications, or cooling devices.

\section{Analgosedation management}

A meeting was held every morning and evening, and the depth of sedation was determined in patients undergoing mechanical ventilation. The depth of sedation was assessed using the RASS $(9,10)$. If increased intracranial pressure was noted or highly suspected, deep sedation targeting a RASS score of -5 with neuromuscular blockade was initiated as needed. The minimum amount of sedatives, such as propofol, midazolam, or dexmedetomidine (DEX), which were necessary to prevent ventilator dyssynchrony and patient discomfort, were used. Analgesics, including acetaminophen, nonsteroidal antiinflammatory medications, and fentanyl, were administered as required. Each physician was responsible for the choice of sedatives. 


\section{Physical restraint}

Physical restraint was initiated based on the RASS score. Examples of physical restraint include Mitten restraints, vests, straps/belts, limb ties, and bedside rails(11).

RASS -3--1: Delirium is assessed using the Confusion Assessment Method for the ICU (CAM-ICU). Physical restraint is considered in patients receiving mechanical ventilation to prevent accidents.

RASS 0: Basically, physical restraint was initiated, but only occasionally when patients are expected to experience delirium at night time to prevent accidents.

RASS $\geq 1$ : Analgesia and sedative drugs were titrated to obtain the RASS - 2 in patients receiving mechanical intubation. In patients as expected to pull or remove tubes or catheters, Mitten restraints were used in addition to limb ties. Further, application of vests was considered to prevent accidental events.

\section{Assessment of delirium in SAH patients in the ICU}

Delirium was assessed by ICU nurses. ICU patients were routinely assessed for the occurrence of delirium through the CAM-ICU. In addition, delirium was defined based on a positive RASS score, or bedside nurse's judgments according to the presence of agitation, hallucination, dangerous behavior, and use of pharmacologic treatments for agitation and hyperactive delirium such as antipsychotic drugs (risperidone or haloperidol). During the ICU stay, delirium was assessed three times a day and when patient's status changed. Delirium during the first $48-72 \mathrm{~h}$ after admission was obtained to clarify the difference of phase between physical restraint requirement and development of delirium.

\section{Data sampling}

The following data were collected: age, sex, $\mathrm{H}$ \& K grade, Fisher score, World Federation Neurological Surgeons (WFNS) grade, treatment modality (coil or clip), sedatives and analgesia administration, RASS score, duration of physical restraint during the first 24-72 $\mathrm{h}$ after admission (no囚intermittent》and continuous use of physical restraint), delirium during the first $48-72 \mathrm{~h}$ after admission, laboratory data on admission, modified Rankin scale (mRS) upon hospital discharge, $\mathrm{DCl}$ rate, duration of mechanical ventilation, duration of ICU stay, duration of hospital stay, and hospital mortality.

Duration of physical restraint was determined during the first $24-72 \mathrm{~h}$ after admission because various treatment strategies (emergency surgical operation or angiography with general anesthesia, deep sedation followed by treatment operation in the next day, computed tomography followed by treatment and so on), were initiated for the first 24 hours; therefore, this phase was excluded in the current study.

Continuous physical restraint was defined as the patients who required continuous physical restraint during the first 24-72 $\mathrm{h}$ after admission. Intermittent physical restraint was defined as the patients who required any physical restraint during the first $24-72 \mathrm{~h}$ after admission.

\section{Outcome measures}


Unfavorable neurologic outcome was considered as the primary end-point, which was assessed using the mRS upon hospital discharge(12). mRS is a global disability measurement tool and comprises seven outcome categories: no symptoms at all, no significant disability, slight disability, moderate disability, moderately severe disability, severe disability, and death. All patients with SAH were examined in real time using mRS upon hospital discharge and listed their medical records. The neurologic outcome was defined as unfavorable when the mRS score was 3-6 and as favorable when the mRS score was $0-2$. The secondary outcome was the occurrence of delirium evaluated by ICU nurses.

\section{Statistical analysis}

To obtain the association between physical restraint in the acute phase and neurological outcomes, patients were divided into three groups based on the amount of time required for physical restraint during the first 24-72 h after admission: no囚intermittent\and continuous use of physical restraint囚Demographic factors and baseline characteristics were summarized using descriptive statistics. The groups were compared using Kruskal-Wallis test or Mann-Whitney U-test, and categorical comparisons were drawn using the Fisher's exact test or chi-square test, as deemed appropriate. Univariate and multivariate analyses were performed to explore independent factors that predicted the unfavorable neurologic outcomes. Covariates of age ( $>65$ years), $\mathrm{H} \& \mathrm{~K}$ grade, treatment modality (coil or clip), and physical restraint were included in the multivariable analysis. The Cochran-Armitage trend test was used to examine the trend between physical restraint during the first 24-72 $\mathrm{h}$ after admission and incidence of delirium during the first 48-72 h after admission. Subgroup analysis was performed on patients with RASS of $\geq-2$ and Hunt \& Kosnik grade of $1-3$. We also repeated the analysis using different definitions of physical restraint during the first $24-72 \mathrm{~h}$ after admission as a continuous variable. Statistical analyses were performed using the JMP version 12 statistical software (SAS Institute, Cary, NC, USA). A two-sided $p$-value $<0.05$ was considered statistically significant for all analyses. Missing data were not replaced or estimated.

\section{Results}

Among 129 patients with SAH who were admitted to the ICU, 119 met the inclusion criteria. Among those who met the inclusion criteria, 18 were excluded due to $\mathrm{H}$ \& $\mathrm{K}$ grade 5 or RASS- 5 without analgosedation or neuromuscular blockade use during the first $24-72 \mathrm{~h}$ after admission. The remaining 101 patients were ultimately included for analyses (Figure 1).

\section{Baseline characteristics of the study population}

The study population included 101 patients (median age, 65 years; 58 [57.4\%] were women). Unfavorable neurological outcomes were observed in 47 patients (46.5\%) (Table 1).

Among them, 46 patients (45.5\%) did not use physical restraint, and 55 (54.5\%) patients used physical restraint during the first $24-72 \mathrm{~h}$ after admission: 26 (25.7\%) intermittent and 29 (28.7\%) continuous. The 
median duration of physical restraint during the first $24-72 \mathrm{~h}$ after admission was $11 \mathrm{~h}$ (interquartile range, 0-48). Their distribution is shown in Supplemental Figure 1.

Baseline characteristics were compared according to three groups of physical restraint during the first 24-72 $\mathrm{h}$ after admission. Significant differences were observed in the outcome at discharge and duration of mechanical ventilator use. The proportion of unfavorable outcome at discharge was $37.0 \%, 53.9 \%$, and $72.4 \%$ in patients with no, intermittent, and continuous use of physical restraint, respectively (Table 1). A comparison of baseline characteristics according to favorable and unfavorable outcomes is shown in Supplemental Table 1.

\section{Association between physical restraint and sedative and antipsychotic medication use}

Among three groups, a significant difference was observed in propofol and DEX use (Table 2). Regarding the evaluation of RASS score, the difference in maximum and minimum RASS score, agitated state (RASS $\geq 1$ ), and deep sedation (RASS score $\leq-3$ ) were also significant among the three groups. Differences in antipsychotic medications use were not significant (Table 2).

\section{Multivariable logistic regression analysis}

Regarding the primary outcome, this study found that continuous use of physical restraint during the first 24-72 $\mathrm{h}$ after admission compared to no physical restraint was significantly associated with unfavorable neurological outcomes at discharge in patients with SAH (odds ratio [OR], 3.31; 95\% confidence interval [Cl], 1.02-11.54; $\mathrm{p}=0.045]$ ) (Table 3).

\section{Association between physical restraint and delirium}

Among all participants, delirium during the first 48-72 $\mathrm{h}$ after admission was assessed in 85 patients and was found in 37 patients (43.5\%). A linear trend was observed in the development of delirium among three groups (4 patients [10.8\%] in the no physical restraint, 12 [50.0\%] in the intermittent, and 21 [87.5\%] in the continuous; $p<0.001$ ) (Figure 2).

\section{Subgroup and Sensitivity analysis}

In patients with RASS of $\geq-2$ during the first 24 to $72 \mathrm{~h}$ after admission, continuous use of physical restraint was significantly associated with unfavorable neurological outcomes at discharge than no physical restraint in patients with $\mathrm{SAH}(\mathrm{OR}, 6.65 ; 95 \% \mathrm{Cl}, 1.71-29.77 ; \mathrm{p}=0.006)$. In patients with $\mathrm{H}$ \& $\mathrm{K}$ grade $(1-3)$ on admission, continuous use of physical restraint during the first 24 to $72 \mathrm{~h}$ after admission was more significantly associated with unfavorable neurological outcomes at discharge than no physical restraint in patients with SAH (OR, 5.41; 95\% Cl, 1.43-23.14; $\mathrm{p}=0.012)$ (Table4). In the analysis using different definitions of physical restraint during the first $24-72 \mathrm{~h}$ after admission as a continuous variable, physical restraint was significantly associated with unfavorable outcomes $(\mathrm{OR}, 1.13 ; 95 \% \mathrm{Cl}$, 1.01-1.28; $p=0.037$ ) (Table 4). 


\section{Discussion}

In this study, continuous use of physical restraint during the first 24-72 $\mathrm{h}$ after admission was found to be more significantly associated with unfavorable neurological outcomes at discharge than no physical restraint in patients with $\mathrm{SAH}$. Continuous use of physical restraint during the first $24-72 \mathrm{~h}$ after admission was also associated with the occurrence of delirium during the first $48-72 \mathrm{~h}$ ICU stay.

A recent study performed by Classen et al. demonstrated that a longer duration of agitation in the acute setting may be associated with more favorable outcomes in patients with SAH with RASS score $>0(6)$. This result seemed to be inconsistent with the results of the current study. Moreover, even in the subgroup analysis limited to patients with RASS $\geq-2$ during the first $24-72 \mathrm{~h}$ after admission in the current study, the stronger conclusion that continuous use of physical restraint during the first $24-72 \mathrm{~h}$ after admission was more significantly associated with unfavorable neurological outcomes than no physical restraint was obtained. However, because agitation was not evaluated directly in the current study, the discrepancy between two studies could not be confirmed precisely.

The increasing exposure of patients to potentially harmful sedative and antipsychotic medications can be reduced with the use of physical restraint(13); however, sedative drug use such as midazolam and propofol was paralleled to physical restraint in this study. In neurocritically ill patients, delirium was independently associated with worse neurological outcome $(7,14)$, and continuous use of physical restraint was associated with the occurrence of delirium in the acute phase in this study. Thus, continuous use of physical restraint during the first $24-72 \mathrm{~h}$ after admission was considered to be more associated with unfavorable neurological outcomes. Another hypothesis could be that although significant difference was not observed, patients with no physical restraint had a shorter ventilation period compared to two physical restraint groups. Thus, more patients with good consciousness levels after initial treatment might have been included in no physical restraint group.

Although physical restraint was the exposure not the intervention in the current study, the hypothesis that continuous use of physical restraint during the first 24-72 $\mathrm{h}$ after admission was more significantly associated with unfavorable neurological outcomes than no physical restraint might be generated. In addition, our subgroup analysis results suggested that its association in patients with non-severe SAH (H\&K grade 1-3) were stronger. However, application of physical restraint is closely associated with sedative and antipsychotic medication use (15-17). Moreover, no RCT has explored the safety and efficacy of physical restraint use in critically ill adult patients(1). Thus, further study to explore the safety and efficacy of physical restraint for patients with SAH will be required. In the study, establishing appropriate outcomes such as biomarker, (S100ß, NSE)(18), post-aSAH syndrome(19), and harmful sedative and antipsychotic medication use to prevent self-extubation, tube dislodgement, and/or medical device removal may be required.

This study has several limitations that should be addressed. First, this was a retrospective single-center study with a small sample size; hence, the possibility selection bias and uncontrolled confounding factors should be considered. Also, some patients received unrecorded physical restraint might have been 
categorized as no physical restraint group. Second, physical restraint criteria were not established. Third, details of devices in physical restraint were not examined due to the small sample size. Finally, as the primary end-point was unfavorable neurological outcome at hospital discharge, differences in the time of evaluation may have affected the results.

\section{Conclusions}

This study found that continuous use of physical restraint during the first $24-72 \mathrm{~h}$ after admission was significantly more associated with unfavorable neurological outcomes than no physical restraint at discharge in patients with SAH.

\section{Abbreviations}

SAH: subarachnoid hemorrhage; ICU:intensive care unit; RASS:Richmond Agitation-Sedation Scale; DCI:delayed cerebral ischemia; DEX:dexmedetomidine; CAM-ICU:Confusion Assessment Method for the ICU; WFNS:World Federation Neurological Surgeons; mRS:modified Rankin scale; OR:odds ratio; Cl:confidence interval

\section{Declarations}

\section{Ethics approval and consent to participate}

This study was approved by the institutional review board of the Kagawa University Hospital (approval number: 2020-053). The requirement for patient consent was waived due to the retrospective nature of the study.

\section{Consent for publication}

Not applicable.

\section{Availability of data and materials}

The datasets used and/or analysed during the current study are available from the corresponding author on reasonable request.

\section{Competing interests}

The authors declare that they have no competing interests.

\section{Funding}

None.

\section{Authors' contributions}


Drs. Akiyama and Inoue contributed equally to this work. TH takes responsibility for the paper as a whole. All authors read and approved the final manuscript.

\section{Acknowledgements}

None.

\section{References}

1. Devlin JW, Skrobik Y, Gelinas C, Needham DM, Slooter AJC, Pandharipande PP, et al. Clinical Practice Guidelines for the Prevention and Management of Pain, Agitation/Sedation, Delirium, Immobility, and Sleep Disruption in Adult Patients in the ICU. Crit Care Med. 2018;46(9):e825-e73.

2. Meyfroidt G, Smith M. Focus on delirium, sedation and neuro critical care 2019: towards a more brain-friendly environment? Intensive Care Med. 2019;45(9):1292-4.

3. Mion LC. Physical restraint in critical care settings: will they go away? Geriatr Nurs. 2008;29(6):4213.

4. Unoki T, Sakuramoto H, Ouchi A, Fujitani S. Japanese Society of Education for P, Trainees in Intensive Care Nursing Research G. Physical restraints in intensive care units: a national questionnaire survey of physical restraint use for critically ill patients undergoing invasive mechanical ventilation in Japan. Acute Med Surg. 2019;6(1):68-72.

5. Reznik ME, Schmidt JM, Mahta A, Agarwal S, Roh DJ, Park S, et al. Agitation After Subarachnoid Hemorrhage: A Frequent Omen of Hospital Complications Associated with Worse Outcomes. Neurocrit Care. 2017;26(3):428-35.

6. Reznik ME, Mahta A, Schmidt JM, Frey HP, Park S, Roh DJ, et al. Duration of Agitation, Fluctuations of Consciousness, and Associations with Outcome in Patients with Subarachnoid Hemorrhage. Neurocrit Care. 2018;29(1):33-9.

7. Oldenbeuving AW, de Kort PL, Jansen BP, Algra A, Kappelle LJ, Roks G. Delirium in the acute phase after stroke: incidence, risk factors, and outcome. Neurology. 2011;76(11):993-9.

8. Connolly ES Jr, Rabinstein AA, Carhuapoma JR, Derdeyn CP, Dion J, Higashida RT, et al. Guidelines for the management of aneurysmal subarachnoid hemorrhage: a guideline for healthcare professionals from the American Heart Association/american Stroke Association. Stroke. 2012;43(6):1711-37.

9. Sessler CN, Gosnell MS, Grap MJ, Brophy GM, O'Neal PV, Keane KA, et al. The Richmond AgitationSedation Scale: validity and reliability in adult intensive care unit patients. Am J Respir Crit Care Med. 2002;166(10):1338-44.

10. Riker RR, Fugate JE. Clinical monitoring scales in acute brain injury: assessment of coma, pain, agitation, and delirium. Neurocritical care. 2014;21(Suppl 2):27-37.

11. Retsas AP. Survey findings describing the use of physical restraints in nursing homes in Victoria, Australia. Int J Nurs Stud. 1998;35(3):184-91. 
12. Banks JL, Marotta CA. Outcomes validity and reliability of the modified Rankin scale: implications for stroke clinical trials: a literature review and synthesis. Stroke. 2007;38(3):1091-6.

13. Shehabi Y, Bellomo R, Reade MC, Bailey M, Bass F, Howe B, et al. Early intensive care sedation predicts long-term mortality in ventilated critically ill patients. Am J Respir Crit Care Med. 2012;186(8):724-31.

14. Naidech AM, Beaumont JL, Rosenberg NF, Maas MB, Kosteva AR, Ault ML, et al. Intracerebral hemorrhage and delirium symptoms. Length of stay, function, and quality of life in a 114-patient cohort. Am J Respir Crit Care Med. 2013;188(11):1331-7.

15. Benbenbishty J, Adam S, Endacott R. Physical restraint use in intensive care units across Europe: The PRICE study. Intensive Critical Care Nursing. 2010;26(5):241-5.

16. De Jonghe B, Constantin J-M, Chanques G, Capdevila X, Lefrant J-Y, Outin H, et al. Physical restraint in mechanically ventilated ICU patients: a survey of French practice. Intensive Care Med. 2013;39(1):31-7.

17. Luk E, Sneyers B, Rose L, Perreault MM, Williamson DR, Mehta S, et al. Predictors of physical restraint use in Canadian intensive care units. Crit Care. 2014;18(2):R46.

18. Hong CM, Tosun C, Kurland DB, Gerzanich V, Schreibman D, Simard JM. Biomarkers as outcome predictors in subarachnoid hemorrhage-a systematic review. Biomarkers. 2014;19(2):95-108.

19. Haug Nordenmark T, Karic T, Roe C, Sorteberg W, Sorteberg A. The post-aSAH syndrome: a selfreported cluster of symptoms in patients with aneurysmal subarachnoid hemorrhage. $J$ Neurosurg. 2019:1-10.

\section{Tables}

Table 1. Comparison of baseline characteristics according to physical restraint during the first 24 to $72 \mathrm{~h}$ after admission 
Variables 


\begin{tabular}{|lllllr|}
$\begin{array}{l}\text { Length of hospital stay } \\
\text { (day) }\end{array}$ & $27(23-$ & $28(22-36)$ & $28(24-35)$ & $27(23-42)$ & 0.892 \\
\hline $\begin{array}{l}\text { Duration of physical } \\
\text { restraint (hour) }\end{array}$ & $11(0-48)$ & $0(0-0)$ & $20(13-36)$ & $48(48-48)$ & $<0.001$ \\
\hline
\end{tabular}

Data are presented as medians (interquartile range, IQR) for continuous variables and $N$ (percentage) for categorical variables.

WFNS, World Federation Neurological Surgeons, mRS, modified Rankin scale; ICU, intensive care unit Table 2. Association between physical restraint and sedative and antipsychotic medications use 
Variables

$\begin{array}{lllll}\text { Total } & \text { No } & \text { Intermittent } & \text { Continuous } & \begin{array}{l}p \text { - } \\ \text { value }\end{array} \\ (n=101) & \begin{array}{l}\text { physical } \\ \text { restraint }\end{array} & \begin{array}{l}\text { physical } \\ \text { restraint }\end{array} & \begin{array}{l}\text { physical } \\ \text { restraint }\end{array} & \\ & (n=46) & (n=26) & (n=29) & \end{array}$

Sedatives and analgesia

$(\%)$

\begin{tabular}{|c|c|c|c|c|c|}
\hline Midazolam & $12(11.9)$ & $5(10.9)$ & $2(7.7)$ & $5(17.2)$ & 0.529 \\
\hline Propofol & $30(29.7)$ & $4(8.7)$ & $10(38.5)$ & $16(55.2)$ & $<0.001$ \\
\hline Dexmedetomidine & $33(32.7)$ & $5(10.9)$ & $10(38.5)$ & $18(62.1)$ & $<0.001$ \\
\hline Fentanyl & $25(24.8)$ & $9(19.6)$ & 5 (19.2) & $11(37.9)$ & 0.150 \\
\hline \multicolumn{6}{|l|}{ Evaluation of RASS } \\
\hline Maximum RASS score & $0(0-1.0)$ & $0(0-0)$ & $0(-0.3-1.0)$ & $1(-1.0-1.5)$ & 0.005 \\
\hline Minimum RASS score & $\begin{array}{l}-2.0 \\
(-4.0--1.0)\end{array}$ & $\begin{array}{l}-1.0 \\
(-1.0--1.0)\end{array}$ & $\begin{array}{l}-2.5 \\
(-4.0--1.0)\end{array}$ & $-4(-4.0--4.0)$ & $<0.001$ \\
\hline RASS score $\geq 1$ (\%) & $36(35.6)$ & $5(10.9)$ & $12(46.2)$ & $19(65.5)$ & $<0.001$ \\
\hline $\begin{array}{l}\text { Duration of RASS score } \\
\geq 1 \text { (hour) }\end{array}$ & $0(0-3.0)$ & $0(0-0)$ & $0(0-7.3)$ & $2.0(0-10.5)$ & $<0.001$ \\
\hline RASS score $\leq-3(\%)$ & $49(48.5)$ & $9(19.6)$ & $13(50.0)$ & $27(93.1)$ & $<0.001$ \\
\hline $\begin{array}{l}\text { Duration of RASS score } \\
\leq-3 \text { (hour) }\end{array}$ & $0(0-40.5)$ & $0(0-0)$ & $0.5(0-31.0)$ & $\begin{array}{l}36.0(14.0- \\
45.0)\end{array}$ & $<0.001$ \\
\hline $\begin{array}{l}\text { Antipsychotic medications } \\
(\%)\end{array}$ & $7(6.9)$ & $1(2.2)$ & $2(7.7)$ & $4(13.8)$ & 0.153 \\
\hline Number of devices ${ }^{a}$ & $\begin{array}{l}7.0(6.0- \\
7.0)\end{array}$ & $7.0(6.0-7.0)$ & $7.0(6.8-7.0)$ & $7.0(6.5-8.0)$ & 0.436 \\
\hline
\end{tabular}

RASS, Richmond Agitation-Sedation scale

adevises: endotracheal tube, central venous catheter, arterial line, peripheral venous catheter, nasogastric tube, urinary catheter, external ventricular drain, lumbar spinal drain, intracranial pressure sensor.

Table 3. Unadjusted and adjusted associations between physical restraint and unfavorable (mRS4-6) outcomes 


\begin{tabular}{|c|c|c|c|c|}
\hline \multirow[b]{2}{*}{ Variables } & \multicolumn{2}{|c|}{ Univariate analysis } & \multicolumn{2}{|c|}{ Multivariable analysis } \\
\hline & OR $(95 \% \mathrm{Cl})$ & $\begin{array}{l}P \text { - } \\
\text { value }\end{array}$ & OR $(95 \% \mathrm{Cl})$ & $\begin{array}{l}P \text { - } \\
\text { value }\end{array}$ \\
\hline Age (>65 years) & $\begin{array}{l}5.62(2.44- \\
13.61)\end{array}$ & $<0.001$ & $\begin{array}{l}7.04(2.58- \\
21.24)\end{array}$ & $<0.001$ \\
\hline Hunt \& Kosnik grade ${ }^{a}$ & $\begin{array}{l}2.18(1.43- \\
3.50)\end{array}$ & $<0.001$ & $\begin{array}{l}2.46(1.49- \\
4.37)\end{array}$ & $<0.001$ \\
\hline Treatment modality (coil vs. clip) & $\begin{array}{l}1.55(0.59- \\
4.19)\end{array}$ & 0.374 & $\begin{array}{l}1.43(0.42- \\
5.03)\end{array}$ & 0.569 \\
\hline \multicolumn{5}{|c|}{$\begin{array}{l}\text { Physical restraint during the first } 24 \text { to } 72 \mathrm{~h} \\
\text { after admission }\end{array}$} \\
\hline No physical restraint & Reference & & Reference & \\
\hline Intermittent physical restraint & $\begin{array}{l}1.99(0.75- \\
5.37)\end{array}$ & 0.165 & $\begin{array}{l}1.13(0.34- \\
3.70)\end{array}$ & 0.835 \\
\hline Continuous physical restraint & $\begin{array}{l}4.48(1.68- \\
12.88)\end{array}$ & 0.002 & $\begin{array}{l}3.31(1.02- \\
11.54)\end{array}$ & 0.045 \\
\hline
\end{tabular}

mRS, modified Rankin scale; OR, odds ratio; $\mathrm{Cl}$, confidence interval

${ }^{\mathrm{a} C o n t i n u o u s ~ v a r i a b l e ~}$

Table 4. Subgroup and Sensitivity analysis of the association between physical restraint and unfavorable (mRS4-6) outcome 


\begin{tabular}{|c|c|c|c|c|}
\hline \multirow[b]{2}{*}{ Models and variables } & \multicolumn{2}{|c|}{ Univariate analysis } & \multicolumn{2}{|c|}{$\begin{array}{l}\text { Multivariable } \\
\text { analysis }\end{array}$} \\
\hline & OR $(95 \% \mathrm{Cl})$ & $\begin{array}{l}P \text { - } \\
\text { value }\end{array}$ & $\begin{array}{l}\text { OR } \\
(95 \% \mathrm{Cl})\end{array}$ & $\begin{array}{l}P \text { - } \\
\text { value }\end{array}$ \\
\hline \multicolumn{5}{|l|}{ RASS $\geq-2(n=82)$} \\
\hline \multicolumn{5}{|c|}{ Physical restraint during the first 24 to $72 \mathrm{~h}$ after admission } \\
\hline No physical restraint & Reference & & Reference & \\
\hline Intermittent physical restraint & $\begin{array}{l}3.02(0.97- \\
9.82)\end{array}$ & 0.057 & $\begin{array}{l}1.69 \\
(0.44- \\
6.40)\end{array}$ & 0.437 \\
\hline Continuous physical restraint & $\begin{array}{l}8.29(2.65- \\
28.87)\end{array}$ & $<0.001$ & $\begin{array}{l}6.65 \\
(1.71- \\
29.77)\end{array}$ & 0.006 \\
\hline \multicolumn{5}{|l|}{ Hunt \& Kosnik grade 1-3 $(n=81)$} \\
\hline \multicolumn{5}{|c|}{ Physical restraint during the first 24 to $72 \mathrm{~h}$ after admission } \\
\hline No physical restraint & Reference & & Reference & \\
\hline Intermittent physical restraint & $\begin{array}{l}2.64(0.87- \\
8.25)\end{array}$ & 0.088 & $\begin{array}{l}1.79 \\
(0.50- \\
6.45)\end{array}$ & 0.371 \\
\hline Continuous physical restraint & $\begin{array}{l}7.25(2.31- \\
25.49)\end{array}$ & $<0.001$ & $\begin{array}{l}5.41 \\
(1.43- \\
23.14)\end{array}$ & 0.012 \\
\hline \multicolumn{5}{|l|}{ Different definition (continuous variable) } \\
\hline $\begin{array}{l}\text { Physical restraint during the first } 24 \text { to } 72 \mathrm{~h} \text { after } \\
\text { admission (OR per each } 5 \text { hours) }\end{array}$ & $\begin{array}{l}1.18(1.07- \\
1.30)\end{array}$ & 0.001 & $\begin{array}{l}1.13 \\
(1.01- \\
1.28)\end{array}$ & 0.037 \\
\hline
\end{tabular}

mRS, modified Rankin scale; OR, odds ratio; $\mathrm{Cl}$, confidence interval

Adjusted factors were the same as those during primary analysis: Physical restraint requirement during the first 24 to $72 \mathrm{~h}$ after admission, age (>65 years), Hunt \& Kosnik grade, and treatment modality (coil or clip).

\section{Figures}




\section{Figure. 1}

129: Subarachnoid hemorrhage patients who were admitted to the ICU

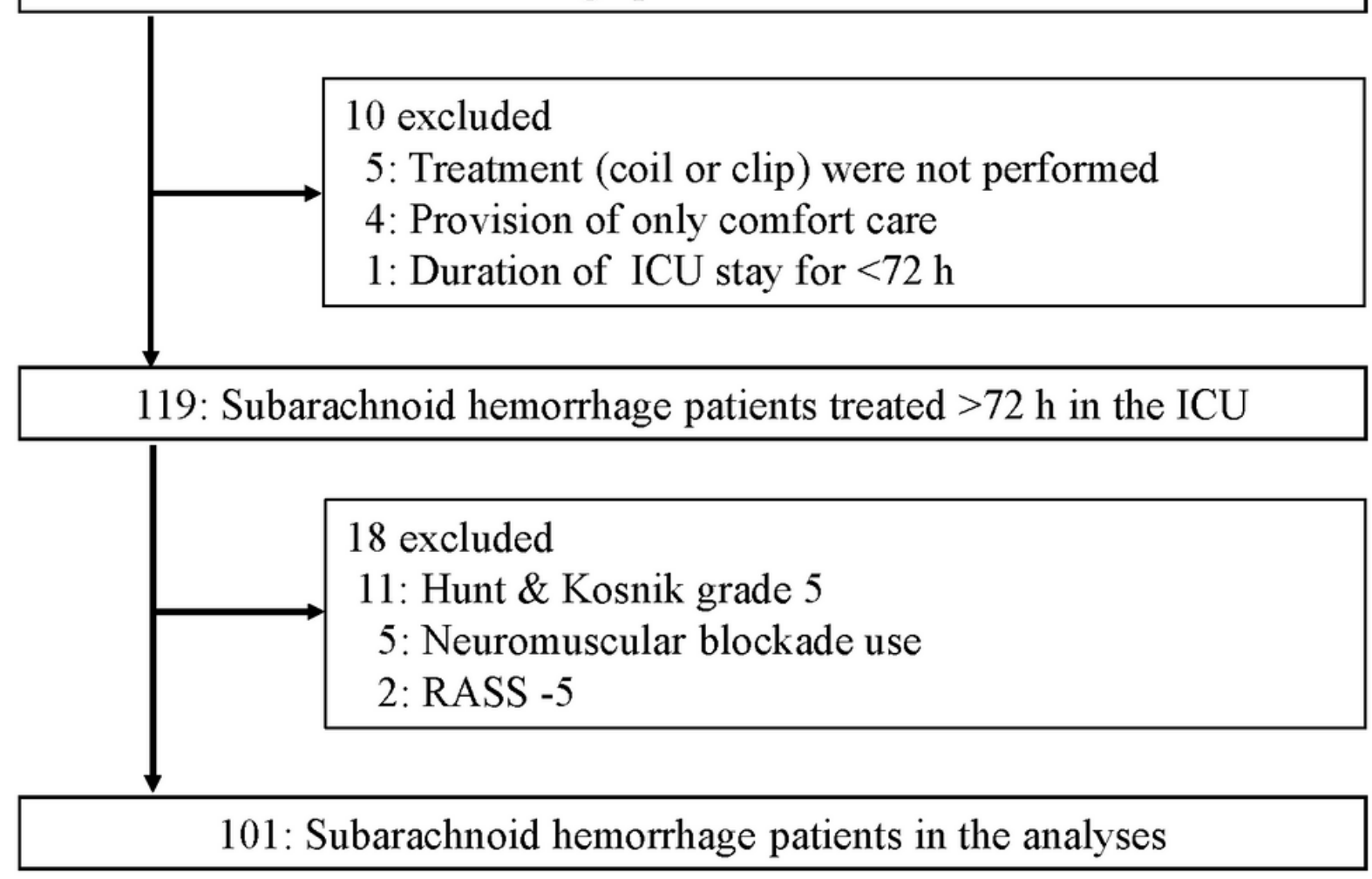

Figure 1

Patient flow. 


\section{Figure. 2}

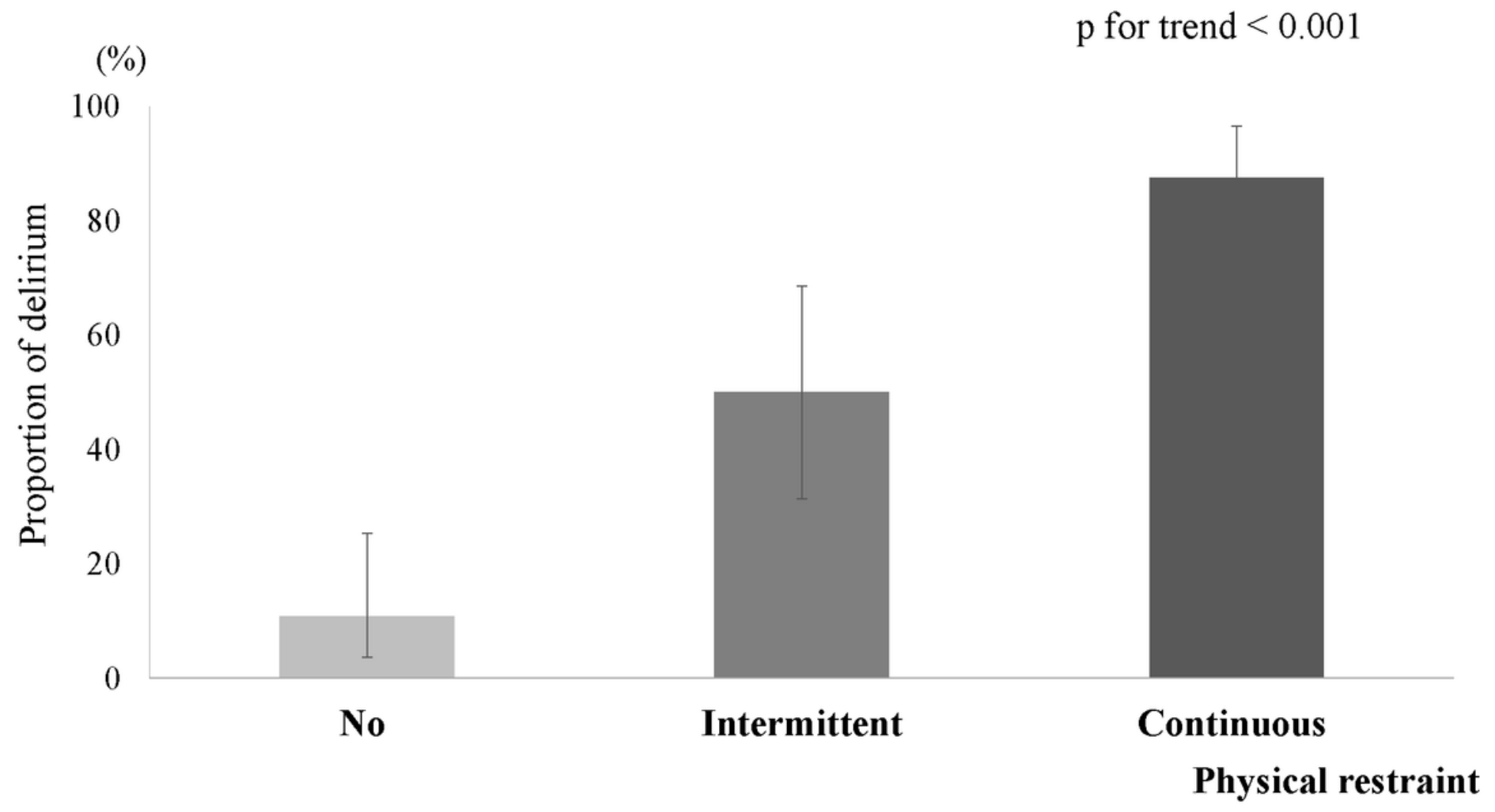

Figure 2

Associations between physical restraint during the first $24-72 \mathrm{~h}$ after admission and delirium during the first $48-72 \mathrm{~h}$ after admission. The proportion of delirium during the first $48-72 \mathrm{~h}$ after admission was 4 patients $(10.8 \%)$ in the no physical restraint, $12(50.0 \%)$ in the intermittent, and $21(87.5 \%)$ in the continuous. Error bars indicate the $95 \%$ confidence interval.

\section{Supplementary Files}

This is a list of supplementary files associated with this preprint. Click to download.

- renameda4379.pptx

- Appendixtable1.docx 